\title{
LA LECTURA DE \\ FR. LUIS DE GRANADA EN EL SIGLO XVIII
}

Vicente LEON NAVARRO 
. 


\section{1.--Introducción.}

A Fray Luis de Granada, hasta la fecha, no se le ha dedicado un estudio de conjunto que abarque los diversos aspectos, tanto religiosos como literarios, sin olvidar las influencias, no sólo a que se ve sometido, sino también las que él a través de su obra ejerce posteriormente. En esta línea hemos planteado y realizado nuestra tesis doctorak11, y en la misma seguimos trabajando y ahondando con resultados alentadores.

En nuestra tesis expusimos cómo Luis de Granada, entre otras fuentes, bebe de Erasmo(2). Pero no solamente por tratarse del famoso humanista, sino porque es el tipo de espiritualidad que sincroniza perfectamente con el deseo real de una reforma de la Iglesia y de la espiritualidad que vuelva a sus raíces primitivas. De ahí, que en el origen del dominico hayamos encontrado otras fuentes de influjo, que manifiestan esa espiritualidad exigente de pureza evangélica en la que estaban interesadas numerosas personas. La influencia erasmista es una más. Sin embargo, Fr. Luis aglutina y sabe dar una impronta personal coherente a todo tipo de influjo.

Su experiencia personal y el conocimiento que tiene del hombre es lo que le lleva a estructurar sus obras, especialmente las castellanas, de una forma pedagógica. Es fundamental enseñar y hacerlo en la lengua que todos conocen. La ignorancia es causa de verdaderos males y errores. Se esfuerza por hacer llegar el mensaje cristiano de la forma más llana y sencilla, que todos puedan entender. En este afán es donde hay que situar sobre todo Libro de Oración y Meditación y Guía de Pecadores. Afán compartido por otros autores del siglo XVI. Así, fundamentará esa espiritualidad, necesaria para todo cristiano en el Antiguo y Nuevo Testamento y en los Santos Padres, cuya huella es permanente a través de sus escritos(3). Sin olvidar esos influjos ya citados anteriormente: erasmismo, corriente espiritual española, misticos nórdicos e italianos, que unas veces cita y otras calla.

Pero al mismo tiempo se prepara una tensa batalla en torno al empleo de las lenguas romances, que termina con la prohibición de leer en estas lenguas las Sagradas Escrituras. Esto se convierte en una pesada carga para quienes ven claro que no es el método a seguir, sea Juan de Avila, Carranza, Luis de León o el mismo Granada, por citar algunos, que inten- 
tan vulgarizar la Biblia a través de sus escritos. De ahl que parte de sus obras sean incluidas en el Indice de Valdés en 1559. Sin embargo, son también muchos los que trabajan para evitar tales traducciones, la exposición en romance de los misterios de la fe, de los sermonarios, de los libros que vulgarizan las cosas divinas o que osan atreversé a comentar la Sagrada Escritura. Son dos concepciones diametralmente opuestas. Piensan estos últimos, seguramente, que el romance no es la lengua adecuada para exponer las cosas santas. Pero se impide asi a los cristianos un acceso directo a las fuentes bíblicas, a su conocimiento, paso previo para erradicar la ignorancia. Piensan, tal vez, que con malos devocionarios es suficiente.

En esta mentalidad quedará inmersa la jerarquía, en líneas generales, con gran deterioro para su imagen tanto pastoral como doctrinal y de funestos resultados posteriores. Pero la semilla de este humanismo cristiano del dieciseis no se perderá, sino que cobrará fuerza especialmente en el siglo XVIII; se redescubrirá, en palabras de A. Mestre, cuyos trabajos sobre este tema son conocidos y Valencia será centro de especial difusión gracias al magisterio de hombres como Marti o Mayáns, cuyo influjo se acreciente a lo largo del siglo.

Nosotros por nuestra parte hemos analizado la influencia del sigio $\mathrm{XVI}$ y el redescubrimiento del humanismo cristiano a través de Fray Luis de Granada y de sus obras, especialmente las castellanas y cómo su influjo espiritual es muy importante, junto con la actividad de Mayáns(4), para entender la reforma de la Iglesia que se produce en la España del dieciocho. Reforma que es fundamental para la sociedad, dada la relación tan estrecha entre religión y sociedad y el control ejercido por la Iglesia ya directamente ya a través del poder establecido.

2.-Ediciones de Fray Luis de Granada.

Esto es lo que nos ha llevado a hacer un breve análisis de las ediciones de que son objeto las obras más importantes del dominico en el siglo de la llustración española, en cuyo proceso de reforma juegan un papel básico. No se trata de un estudio erudito, pues creemos que semejante tarea exige un trabajo monográfico amplio que rebasa, con mucho, nues- 
tro propósito actual. A ello se dedicó el P. M. Llaneza con muy buenos resultados(5). Tampoco pretendemos contabilizar cada edición minuciosamente, sino observar una tendencia de ascenso o descenso de las obras y cuáles pueden ser éstas. Con ello intentamos conocer en qué medida la producción de las obras de Luis de Granada sufren variaciones del siglo XVII-considerado como un siglo de decadencia-al siglo XVIII y también, pues lo consideramos importante, cuál es la influencia granatense en Francia a través de estas ediciones, a fin de poder explicar, quizá, el fenómeno de ciertos influjos franceses en la España del Siglo de las Luces(6).

A lo largo del siglo XVII los volúmenes más editados se reducen, casi siempre, a Guía de Pecadores, Libro de Oración y Meditación y luego, Memorial y Adiciones al Memorial. A veces acompaña la Vida de Luis de Granada, escrita por el licenciado Muñoz. Se trata, pues, de los libros más representativos y de mayor repercusion en los fieles, donde se halla compendiada, de una forma más clara, la vida espiritual del cristiano $\mathrm{y}$, además, estar escritos en romance, con una ausencia total de citas latinas.

Las ediciones de obras, más o menos completas, en el siglo XVI|(7), se reparten de manera muy desigual. Se producen vacios sensibles. Asi, desde 1625 a 1646 no se editan. Tampoco desde 1659 a 1674 y, lo mismo sucede, de 1679 a 1701, abarcando periodos de veinte años aproximadamente. Durante este siglo se observan unas 12 ediciones de "obras" que contrastan, sin lugar a dudas, con las más de 60 que se realizan en Francia, con una regularidad total, a lo largo del mencionado siglo hasta finales, 1690 en concreto, fecha en que prácticamente quedan truncadas, aunque sigan editándose algunos títulos sueltos. Da la impresión de que «las obras completas" ya no interesan. En este sentido podría pensarse que en Francia surgen nuevas escuelas de espiritualidad. Así, diría el abate Clément a Estanislao de Lugo en su correspondencia:

"Toda enseñanza se la reparten tres familias bien distintas, cada una de las cuales ha hechado profundas raices. La primera es la molinista, que desde 1713 y paso a paso ha ido ganando el mayor terreno en las instituciones teológicas que se intentan introducir en Francia; la de Poitiers...(8).

En este análisis de la situación de la Iglesia en Francia a finales del siglo XVIII, Clément es claro. No podemos precisar si ambos fenómenos, 
aumento del molinismo y caida de la influencia espiritual granatense, van unidos, pero posiblemente asi sea(9). No hay que olvidar que Luis de Granada es el autor español más editado en el vecino país a lo largo del siglo XVII.

En la misma línea de Clément podemos entender las palabras del obispo de Barcelona, José Climent, tan unido a la obra del dominico en su Carta Pastoral que sirve de prologo a la Retórica Eclesiástica de Luis de Granada, traducida al castellano. Señala el obispo la recomendación del célebre Bossuet a sus feligreses de que leyesen las obras de los venerables Granada y Avila, para seguir luego diciendo:

«Sin rubor, pues, y con ingenuidad podemos confesar que la predicación de la Divina palabra en el siglo pasado perdió en España aquella majestad y solidez que tuvo en el antecedente. Me parece que podemos gloriarnos de que los Sermones del Venerable Granada, en parte, contribuyeron a que se estableciera o restableciera en Francia la Elocuencia Sagrada, pues fuera de que sabemos, tres veces se vertieron en aquella lengua, los mismos franceses nos dicen, que en los Sermones de sus mejores predicadores se leen copiadas páginas enteras de las del V. Granada. Y a más sabemos que su Retórica se vertió en francés en el siglo pasado»(10).

Con ello el obispo Climent viene a destacar el abandono de este autor a lo largo del siglo XVIK11) en España y la influencia, sin embargo, que ejerció en Francia. $Y$ así parece deducirse del número de ediciones y de las palabras del traductor de la Retórica expone en su pequeño prólogo inicial(12). No queremos señalar solamente la importancia de esta obra, en boca de su traductor, sino constatar el hecho de su aprecio y, por tanto, la influencia en Francia, cuando en España apenas si era "conocida" y estimada, al igual que sucedia con otras obras del dominico y de nuestros clásicos del siglo XVI. Pensamos que aqui radican muchos aspectos, no totalmente esclarecidos, de la influencia francesa en la España de la llustración. 


\section{a.-Obras generales.}

El número de "obras completas" que se editan en el siglo XVII(13) es superior al del siglo XVII, pero sin que la diferencia sea muy grande. Si en el siglo XVII hemos contabilizado 12 ediciones-sin tener en cuenta la de Amberes-. En el XVIII suben a 16, contando la de Madrid-Nápoles, editada por Antonio Parrino con 12 volúmenes, que justamente con las 2 que aporta Tomsich(14) - una de 1703 y la otra de 1771-haría un total de 18 ediciones. Este incremento, si bien notorio, no es espectacular, teniendo en cuenta las caracteristicas del siglo XVIII tanto cultural como religiosamente, al tiempo que se da un mayor apoyo a las ediciones de libros. Sin embargo, observamos que el número de volúmenes, en términos generales, es mayor en este siglo que en el anterior. Asi podemos indicar, primero, un mayor número de ediciones y también de volúmenes por edición; segundo, que las ediciones del siglo XVIII se hacen siguiendo, en gran parte, las del $X V I I$, sobre todo en los que se refiere a los prólogos de fray Dionisio Sánchez Moreno y la vida de Luis de Granada, escrita por el licenciado Muñoz, que es la que realmente alcanzó fama; tercero, señalar la edición de 1711 , porque en ella intervienen diversos impresores, con un total de 27 volúmenes, la mayor de todo el siglo. Empieza con la Guía de Pecadores y finaliza con la Vida de Fray Luis de Granada por el Licenciado Muñoz. Esta edición fue obra de D. Francisco Piquer(15).

La mayor cantidad de ediciones con respecto al siglo XVII no impide que se den ciertas épocas de ausencia editorial de estas obras, según se observa; así, 1739-1752, 1789-1800. Hay que destacar que en estas "obras generales" no aparece ningún estudio analítico de la obra del dominico. Se alaba su figura, se le llama "singular honor de la orden de predicadores", "gloria inmortal de nuestra España" y otros muchos elogios entre los que destacan los de santos contemporáneos, pero nada más. Todo se reduce a eso. Se tiende a repetir clichés de ediciones anteriores.

\section{b.-Libro de Oración y Meditación.}

Esta obra no aparece como excesivamente importante en el siglo XVII. Contamos 12 ediciones, teniendo como centros principales a Madrid y Barcelona. Pero de estas 12 al menos 4 coinciden con las fechas de las 
"obras generales", por to que pensamos que este libro aparecería editado como obra independiente unas 8 veces.

En Francia hemos contabilizados otras 12 apariciones, sólo que, en este caso, no hemos constatado ninguna repetición como en el caso español. Además, si bien en el vecino país las "obras generales" se cortan en 1690, el Libro de la Oración y Meditación continúa editándose hasta 1704.

En el siglo XVIII cambia la situación considerablemente. En España este Jibro adquiere un gran auge y un fuerte despertar, indicativo de la importancia que va adquiriendo la oración mental(16). Observamos alrededor de 40 ediciones a lo largo del siglo. De ellas una vez tan sólo hemos constatado repetición con las «obras generales»; se trata de la edición de 1757, en la imprenta de Manuel Martín. Frente a este auge español contrasta el agotamiento de las ediciones francesas a partir-como hemos indicadode 1704. En España la regularidad es total a excepción del bache que se produce entre 1729 y 1749.

Según Palau, en el caso de este libro, es la edición de 1705 la que sirve de modelo a las siguientes, hasta principios del siglo XIX. Impresa en Barcelona, en casa de Joseph Teixidor, es seguida en las restantes, independientemente del lugar de su edición. Con ello, insistimos, se observa que no hay un estudio importante sobre esta obra y, por tanto, se cae en lo que se hacía en ediciones anteriores. De esta forma aparece también como "clásico" el prólogo a cargo del P. Sánchez Moreno sin variación.

No hay que olvidar la labor del impresor Plácido Barco-editor también de los Sermones del dominico, traducidos al castellano-, que en 1785 llegará a editar el Libro de la Oración y Meditación tres veces. Este auge tiene su explicación en la valoración cada vez mayor que se hace de Luis de Granada y de la oración mental. En muchos colegios, seminarios y casas de recogimiento se impone como libro de lectura matinal, base de la oración mental o, también, como lectura en el comedor durante las horas de las comidas(17). Además, esta obra es fuente de inspiración de otros muchos pequeños libros - tipo devocionario, más práctico y asequible a la mayoría de los fieles-que se nutren de la doctrina del dominico y que a lo largo del siglo tuvieron gran difusión, como Breves Instrucciones y oraciones para disponerse y recibir el Sacramento de la Penitencia y Comunión, editado en 1775, siendo expurgado en 1785 por la autoridad eclesiástica, o Compendio del Libro de la Oración. 
c.-La Guía de Pecadores.

Obra de singular importancia y clave del pensamiento de Granada, no tuvo en España apenas difusión ni resonancia en el siglo XVII. Palau señala 4 ediciones, mientras en Francia, durante igual período de tiempo se editó 34 veces. Esta situación cambia en el XVIII, Ilegando a 19 ediciones, sin citar las dos de Nápoles, de las cuales solamente 3 coinciden con las "obras generales", por lo que se obtendría un total de 16 ediciones. Esta cantidad está muy por debajo del Libro de la Oración, aunque, indiscutiblemente, supone un aumento considerable. Resulta también curioso que sea esta obra la que más se siga editando en Francia en el XVIII, por lo menos hasta la mitad de la centuria, llegando a las 16 ediciones.

El Libro de la Oración y la Guía de Pecadores son, sin lugar a dudas, las obras más importantes de Luis de Granada y fuente constante de inspiración de predicadores y de hombres dedicados a la oración y al recogimiento(18). Indica Palau que "tanto es así que es frecuente entre los bibliofilos y en las tertulias que se originan en las librerias de viejo, recordar los innumerables casos de célebres personajes calificados de heterodoxos, y sin embargo, seducidos por el admirable estilo y las riquezas literarias de la Guía de Pecadores y el Libro de la Oración y Meditación. Es corriente entre los aficionados a los buenos libros comentar que el Abate Marchena y el famoso orador D. Emilio Castelar llevaban consigo, en calidad de relicario, el Libro de la Oración(19).

\section{d. -Otras obras.}

No todas las obras de Luis de Granada siguen una misma evolución. El Memorial, por ejemplo, desciende en el número de ediciones del siglo XVIII con respecto al siglo anterior, en paralelismo con lo que sucede en Francia. En el siglo XVII en España se dan unas 10 ediciones y unas 12 en el vecino pais, mientras que en el dieciocho se reducen a 4 tanto en el caso francés como en el español. 
Idéntico proceso se observa con la Introducción del Simbolo de la Fe, a pesar de ciertas recomendaciones como la de Jovellanos en el Reglamento para el Colegio de Calatrava para su utilización. En el siglo XVII se pueden observar 16 ediciones, al tiempo que en el XVIII éstas se ven reducidas a 3. Igual sucede en Francia, aunque el número sea superior al de España con 33 en el XVII y 5 en el XVIII.

Dos obras adquieren especial relevancia a pesar de todo, los Sermones, por una parte, y la Retórica Eclesiástica, por otra. En cuanto a los primeros es destacable la labor del valenciano Juan Bautista Muñoz que editó y prologó Concionum de Tempore y Concionum de praecipuis sanctorum festis(20), pero únicamente en latín, privando a una buena parte del clero de su aprovechamiento pastoral. No será hasta finales del siglo-17901793 - cuando Pedro Duarte traduzca los primeros con el título de Sermones de Tiempo. La edición de Juan Bautista Muñoz tiene la importancia de no limitarse a reeditar, sino que hace un estudio del problema de la predicación, de los predicadores, de la ignorancia y de sus consecuencias, asi como de la voluntad de subsanar los fallos que observa. Rompe, de esta forma, con la tradición de repetir siempre lo mismo y de situarse en su época y analizarla.

El resto de las obras dedicadas a la predicación son de menor entidad, si bien escritas en castellano, como Trece Sermones y otras de este tipo. Admira constatar, que esta parte de la obra de Luis de Granada, valiosa para la predicación del siglo XVIII, ni se edita con la largueza que merece, ni se traduce hasta la última década del siglo, como hemos señalado. En este sentido constatamos que no son los Sermones lo que más se imita sino otras obras, que se convierten en fuente de inspiración, como las ya mencionadas Guia de Pecadores y Libro de la Oración.

Apenas son editadas obras como Collectanea Moralis Philosophiae y Silva Locorum-citadas, además, con parquedad tanto en el siglo XVII como en el XVIII-. La mejor edición de éstas corre a cargo también de Juan Bautista Muñoz en 1755 y 1771 respectivamente. A cada obra precede un prólogo suyo en que analiza los problemas más importantes, al igual que en Concionum. 
Fianalmente, Ecclesiasticae Rhetoricae sive de ratione concinandi libri sex. Según Mayáns(22) y Climent esta obra era difícil de encontrar en el siglo XVIII, además de estar escrita en latín, hechos que impedian acceder con facilidad a su lectura y posesión. Una de las ediciones más importantes en latín es la realizada por el ya mencionado valenciano Juan Bautista Muñoz en 1768 con un importante prólogo. En él, tomando como punto de arranque la obra de Luis de Granada, revela toda una pedagogía orientada al acierto y al progreso en los estudios, potenciando a los clásicos latinos y griegos y buscando siempre la sabiduría. A ésta, según los paganos conduce la filosofía, pero no la filosofía escolástica-que se estudiaba en la época-y que según Muñoz "quae in abusum est», sino la Lógica, esto es la que dirige la mente y forma el juicio. Tras la Lógica viene la Crítica, "...ars certe praeclarissima, atque oratori sacro penitus necessaria», Lo importante, pues, para este valenciano es el establecimiento de la verdad por encima de todo, su búsqueda(23), aunque para ello se exponga al nombre que los escolásticos conceden a los que defienden tales ideas, como es el de impíos. Tales argucias escolásticas no amedrentan a un hombre como Muñoz comprometido en el progreso cultural de su época.

Será, sin embargo, la edición de 1770, en castellano, la que adquiera mayor interés y difusión, a cargo del obispo de Barcelona José Climent, precedida de una Carta-Pastoral sobre la importancia de la predicación y el valor de la obra del dominico. A partir de este momento, las ediciones en castellano se suceden, 1772, 1775, 1777, 1778, 1782, 1793... En esta línea estaba también la Carta Pastoral que el obispo de Salamanca, Felipe Bertrán, escribía a su clero y feligreses en 1764. Su doctrina en gran parte estaba sacada de la Retórica de Granada.

En toda esta pequeña exposición observamos algunos puntos dignos de ser reseñados. En primer lugar, que la influencia de Fray Luis de Granada en el siglo XVIII es más importante que en el siglo anterior, si bien nunca deja de ser notable. En casi todas sus obras se percibe un aumento considerable de ediciones, a excepción de la Introducción del Símbolo de la Fe o del Memorial. Adquieren especial relevancia Guía de Pecadores y Libro de la Oración y Meditación, como claramente significativos y prototipo de la espiritualidad granatense. En segundo lugar, es necesario indicar la gran cantidad de ediciones que de las obras del dominico se hacen en 
Francia a lo largo del siglo XVII frente a la parquedad de esas mismas ediciones en España. Aquí, con ser la patria de Granada se va muy a la zaga de lo que hacen los franceses. De alguna forma esta influencia española en el país vecino repercutirá de nuevo en España en el siglo XVIII.

\section{e.-Los prólogos.}

Ya hemos señalado anteriormente que la mayor parte de las ediciones de las obras de Granada a lo largo del siglo dieciocho, repiten los prólogos hechos en el siglo anterior, o incluso, en el mismo XVIII. Entre estos prólogos es necesario destacar algunos, como la vida del dominico, escrita por el Licenciado Muñoz, de gran valor. De singular importancia son los que hacen Juan Bautista Muñoz y José Climent. Consideramos que el resto tienen escaso interés y, algunos de ellos, son de simple compromiso, tales son los escritos por el P. Sánchez Moreno o los que hacen ciertos editores de las obras.

Fr. Dionisio Sánchez Moreno, también dominico, tiende siempre a ensalzar la orden a la que pertenece y la figura máxima de ella, Santo Tomás de Aquino. Para elogiar a Luis de Granada recurre a las citas de personajes como San Francisco de Sales, San Carlos Borromeo, etc., al igual que lo hacen otros prologuistas. Carecen, por tanto, de sentido crítico y de análisis valorativo de la obra. Recomendará, como lo hacía San Francisco de Sales que se tenga a Granada todo entero y sea éste un segundo breviario, - como San Carlos Borromeo, que no tenía otra teología para predicar y recomendaba sus obras para alcanzar la verdadera devoción. Este es el esquema también que sigue en los prólogos de las distintas obras. Asi:

"...y el que quisiere conseguir estos maravillosos efectos, se habrá de ejercitar en ellas; y esto es lo que hacen las Sagradas Reigiones, las cuales para sus continuos ejercicios de la Oración, tan fructuosos, leen estas Meditaciones de V, P. Maestro Fr. Luis de Granada, y con ellas crían sus hijos tan agradables a Dios, que son resplandecientes estrellas en el firmamento de la Iglesia. Y ésto debemos hacer todos, si queremos el acierto en nosotros y en las almas que corrieren por nuestra cuentan. 
Este tipo de recomendaciones nos parecen demasiado clásicas, en el sentido de que se pueden decir de otros muchos autores. Falta, pues, ese estudio singular, tan necesario para entender la importancia de la obra y de la figura de Luis de Granada. Y es en esta línea en la que abundan la mayor parte de los prólogos o dedicatorias. Ello sucede con la dedicación y prólogo del Convento de Jesús y Maria de Valverde, sonde se aprecia un lenguaje entre milagroso y religioso-beato-sentimental o, incluso, con el del Convento de Santo Domingo de 1719.

f.-Editores de las obras de Luis de Granada.

Hay un interés creciente entre los editores del siglo XVIII por poner en manos del público lector las obras de los autores más ilustres con el fin no de distraer, sino de formar. En esta línea las obras de Luis de Granada tienen una doble dimensión, literaria y religiosa, que las hacen objeto de especial atención a lo largo de todo el siglo. No faltan, pues, los que editan profusamente las obras del dominico. Sin embargo, los centros más importantes son Madrid y Barcelona, aunque Valencia, Salamanca, Valladolid, Pamplona, Palma de Mallorca..., se hacen eco de la importancia de este autor.

En Barcelona, que durante el siglo XVII había habido una labor editorial de gran importancia, cede su primacía en beneficio de Madrid en el siglo XVIII, destacan editores como Iván Pablo Martí, Joseph Giralt, Joseph Teixidor, Rafael Figuero, Pablo Campíns, Tomás Piferrer-labor continuada por su esposa-, María Angela Martí, Sierra y Martí, Joseph Llopis y J. Jolís y B. Plá con la edición en castellano de la Retórica, mandado traducir por el obispo Climent y que tendría numerosas ediciones. De la misma imprenta saldria también Guía de Pecadores. La mayor parte de estos editores sacan a la luz las dos obras principales de Libro de la Oración y Guía de Pecadores y algunos de ellos en varias ocasiones.

En Madrid el espectro de editores es más amplio. Destacan Manuel Martín, Antonio Parrino, Antonio Sancha, Viuda de Ibarra y Plácido Barco López-labor continuada por su viuda que en 1803 aún editará el Libro de la Oración. Estos editores desarrollan una gran actividad. Editan las obras 
generales y los libros más significativos numerosas veces. Siguen otros como Herederos de la viuda de Juan García Infanzón, Antonio Pérez Soto, Manuel Fernández, Pantaleón Aznar, Gerónimo de Estrada, Francisco Otero, Lorenzo Francisco Mojador, Pedro José Alonso y Padilla, Pedro Marín, Santos Alonso y Francisco Manuel de Mena(24), sin olvidar el papel desempeñado por la Imprenta Real.

En Valencia el trabajo de Juan Bautista Muñoz, que revisa y prologa las obras latinas de Luis de Granada se lleva a cabo en la imprenta de José de Orga-dirigida a su muerte por su viuda y luego por J. y T. de Orga-. En 1768 salén de sus prensas dos ediciones distintas de la Rhetórica; una sin prefacio y la otra la preparada por Muñoz. También en casa de Joseph Garcia se habia editado en 1734 Sermón en que se da aviso, que en las caidas públicas...

Finalmente, en Salamanca, Francisco Toxar; en Valladolid, Tomás de Santander; en Pamplona, Joaquín de Domingo, Pascual Ibáñez, Tomás Carmeño; y en Palma de Mallorca, Bauçá, imprimen y sacan a la luz obras de Luis de Granada.

\section{NOTAS:}

(1) Tesis doctoral leida en mayo de 1983 con el titulo Influjo y pervivencia de Fray Luis de Granada en el siglo XVIII español. Universidad de Valencia.

(2) Aspectos también señalados, en parte, por M. BATAILLON, Erasmo y España. Estudios sobre la historia espiritual del siglo XVI. México, 1960, 2. ${ }^{a}$ edición.

(3) Sobre este tema hay que citar a A. HUERGA, La huella de San Buenaventura en Fray Luis de Granada. F.U.E. M. 1976.

(4) G. MAYANS Y SISCAR, Oración en alabanza de las obras de Don Diego Saavedra, Valencia, 1725. Es de notar el papel desempeñado por Mayáns en poner de relieve el significado de Granada y su obra: “España es deudora de inmortales alabanzas al V.P. Fray Luis de Granada que fue el primero que con lección vastísima, diligencia suma y ardientísimo deseo de persuadir a la virtud y desterrar el vicio, dio fuerza, eficacia y natural dulzura al lenguaje español". Constantemente llama a su imitación. A. MESTRE, «El redescubrimiento de Fr. Luis de León en el siglo XVIII", Bulletin Hispanique, LXXXIII (1981), 5-64.

(5) M. LLANEZA, Bibliografia del V.P. M. Fray Luis de Granada de la Orden de Prdicadores. Salamanca, 1926, 4 vol. 
(6) Para este estudio hemos seguido, fundamentalmente, las ediciones aportadas por A. PALAU Y DULCET, en Manual del librero, Hispano-americano, 19 vol. hasta 1967. Conviene aclarar que cuando éste habla de obras no se refiere siempre a obras completas, sino a parte de la obra en la mayoria de los casos. De ahí que lo entrecomillemos: "obras" u cobras generales".

(7) Destacan como centros importantes Barcelona-con el impresor Sebastián Cormella-y Madrid.

(8) Cita tomada de P. DEMERSON, María Francisca de Sales.(Condesa del Montijo). Una figura de la llustración. M. 1975, pp. 269.

En esta linea pretendemos realizar un estudio en profundidad sobre la influencia de Luis de Granada en los autores franceses del siglo XVII.

(10) J. CLIMENT, "Carta-Prólogo" a Los seis libros de la Retórica eclesiástica o de la manera de predicar, de FRAY LUIS DE GRANADA, Barcelona 1770.

(11) Estamos, en estos momentos, trabajando sobre la incidencia real de Luis de Granada en el siglo XVII, un vacio que resta por llenar.

(12) J. CLIMENT, "Carta-Prólogo»..., prólogo inicial del traductor: "Finalmente juzgo que, vertida en español esta Retórica, nos libramos los españoles del cargo que nos hacian los extranjeros, de que haciamos menos aprecio de una de las obras más preciosas y excelentes de nuestra Nación, que el que ellos hicieron, asi reimprimiéndola como vertiéndola en su propia lengua».

(13) En este siglo Madrid adquiere la primacía editorial de las obras de Granada sobre Barcelona con editores como Manuel Martín, Sancha, Imprenta Real.

(14) G. M.. TOMSICH, El Jansenismo en España. Estudio sobre las ideas religiosas en la segunda mitad del siglo XVIII, p. 74. M. 1972.

(15) G. MAYANS Y SISCAR, Epistolario II. Mayans-Burriel. (Transcripción, notas y estudio preliminar de Antonio Mestre), p. 291, Valencia, 1972. "La dedicatoria al duque de Huéscar me ha hechizado, no he leido muchos días ha cosa que tanto me deleite y esto es que lei la carta que el $P$. fray Luis de Granada escribió a la duquesa de Alba consolándola sobre la muerte del héroe de sus obras en la edición que hizo D. Francisco Piquer en 1711،.

(16) Estamos trabajando en el esclarecimiento de la espiritualidad del siglo XVII. A priori no podemos determinar que en este siglo se vea reducida la práctica de la oración mental ni que la obra de Granada sea exclusivamente la que indique su mayor o menor grado de práctica. Hay otros actores y más factores.

(17) Baste citar en este sentido que la mayor parte de las Constituciones de los Seminarios, a partir de la reforma de los planes de estudios de 1767, recogen la obra espiritual de Luis de Granada; así las de Zamora, las de Salamanca, las de Orense, las de Cádiz, etc. Las del de Valencia los recogen especialmente para los ejercicios espirituales, oponiéndose de esta forma a la práctica habitual de utilizar el método ignaciano.

(18) Queremos destacar cómo estas dos obras influyeron de forma decisiva en dos valencianos (nacidos en Castellón), José Climent y Felipe Bertrán, condicionando toda su obra pastoral posterior; desempeñando ambos cargos de especial relieve, obispo de Barcelona el primero y obispo de Salamanca e Inquisidor General el segundo. Más amplio en nuestra tesis, Influjo...

(19) A. PALAU Y DULCET, Manual del librero..., 360. 
(20) Se editan en Valencia en casa de J. y T. Orga.

(20) Pedro Duarte anota en su prólogo: «salen a la fuz y se presentan al público en nuestro idioma los sermones latinos del incomparable Español, el Venerable Padre Fray Luis de Granada, cuando está llena y acaso sobrada nuestra nación de traducciones extranjeras...".

(22) El interés de Mayans por las obras de Granada es constante. En carta a Campomanes recomienda al editor José Gómez que quiere editar las obras latinas del dominico a sus expensas para que se difundan.

(23) En su primera obra De recto philosophiae recentis in theologia usu, Valencia 1767, expone claramente su espiritu moderno y su deseo de rechazar cualquier idea preconcebida para formar su propio pensamiento. Atacará a los que se contentan con alimentos-escolástica-escolástica que más bien son propios de animales, como las bellotas, que aferrados a las ideas preconcebidas, parecen ostras adheridas a rocas, incapaces de mover un dedo por buscar la verdad. En su labor editora Muñoz contó con la ayuda de otro valenciano, fray Luis de Galiana, a cuyo cargo corrió el trabajo critico de las ediciones conocidad de Luis de Granada en lengua latina.

(24) Francisco Manuel de Mena edito, según testifica en 1754, Meditaciones para los dias de la semana. Dato facilitado por François López. 